\title{
POETRY
}

\section{THE TURNCOAT}

I saw a rabbit on the lawn today.

And what was strange about that? you say,

Well, nothing really at all, except

That he was brown as you'd expect,

But his ears were white.

Now l've never spoken to him before Though l'd seen him sitting by the door During the winter. In sober white Early morning and late at night, But now his colour was brown.

I had to say to him, "Look Bunny Please don't think I'm being funny But make your mind up about your ears And turn them brown, For summer nears and white's not right!"

He looked at me as much to say

"Mind your own business," and hopped away

But as he went he turned his back On me, and I saw as he hopped on another tack

His scut was also white.

I haven't seen him again this week Maybe he thought what I said was cheek But in this world you've got to be Either one thing or the other you see.

\section{AND THIS RABBIT WASN'T!}

- Dorothy M. Lacey, Box 1855, Tisdale, SK. TOE 1 TO

\section{PERFECT PICTURE}

Past the boat

In a dead man's float

A shining rock

Began to slip

Then dip

Beneath the dock.

Then arose

An ebony nose.

Glassy eyes peered

Feline sharp ears

Reared...

Nonchalant,

This gallant,

Sensing human presence,

Pretending not to know,

Proceeded with the show.

Slunk below...

Then the watery curtain parted

And upstarted

The star

To centre stage.

On that rocky boulder

Light-footed stood

From tail to shoulder.

Front paws cupped;

Chin tilted up,

The beaver chose

To pose.

- Margaret P.M. Luke, Box 206, Porcupine Plain, SK. SOE $1 \mathrm{HO}$

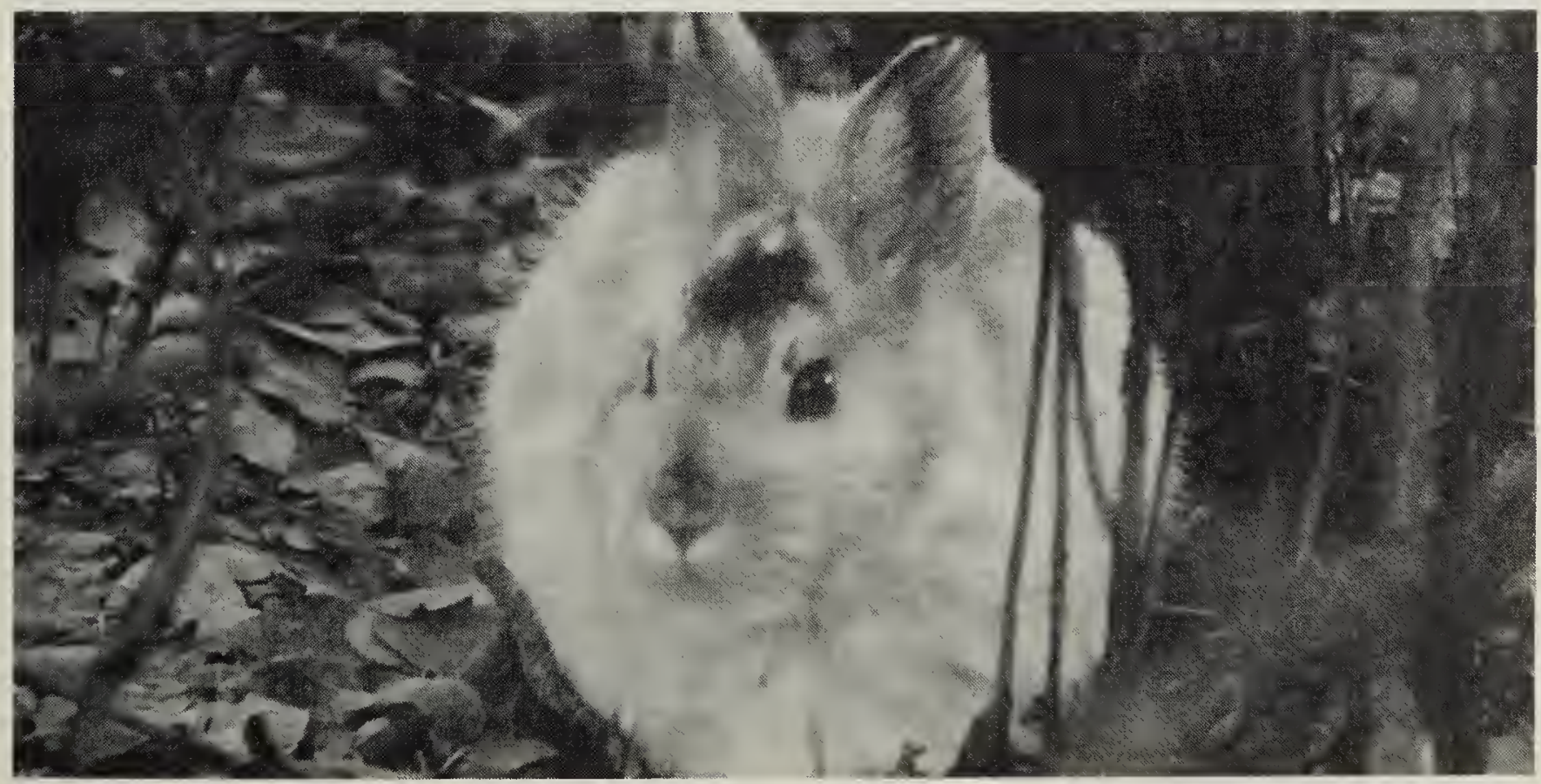

